\title{
Succeeding at home and abroad: accounting for the international spillovers of cities' SDG actions
}

Rebecka Ericsdotter Engström (iD) ${ }^{1 凶}$, David Collste (iD ${ }^{2,3}$, Sarah E. Cornell (iD) ${ }^{2}$, Francis X. Johnson (iD ${ }^{4}$, Henrik Carlsen (iD) ${ }^{4}$ Fernando Jaramillo iD $^{5}$, Göran Finnveden ${ }^{6}$, Georgia Destouni $\mathbb{D}^{5}$, Mark Howells ${ }^{7,8}$, Nina Weitz ${ }^{4}$, Viveka Palm ${ }^{6,9}$ and Francesco Fuso-Nerini (iD) ${ }^{1}$

Cities are vital for achieving the Sustainable Development Goals (SDG), but different local strategies to advance on the same SDG may cause different 'spillovers' elsewhere. Research efforts that support governance of such spillovers are urgently needed to empower ambitious cities to 'account globally' when acting locally on SDG implementation strategies.

npj Urban Sustainability (2021)1:18; https://doi.org/10.1038/s42949-020-00002-w

\section{INTRODUCTION}

Global achievement of the United Nations 2030 Agenda for Sustainable Development (the 2030 Agenda) depends on local action ${ }^{1}$. However, the interconnectedness of the Agenda's Sustainable Development Goals (SDGs) ${ }^{2}$ in today's globalized world implies that ambitious actions to advance on one SDG in one city create 'spillovers': cross-border impacts that can affect the advancement of the same or other SDGs elsewhere ${ }^{3,4}$. Such spillovers have been found to be strategy-dependent: different strategies for meeting a given SDG target within a city may create different spillovers ${ }^{5}$.

Available assessments of SDG interlinkages assert that different actions for advancing one SDG have different effects on other $\mathrm{SDGs}^{6-8}$. However, these assessments do not systematically differentiate between local and international effects. Proposed methods for spillover accounting at national level, as part of national SDG performance indexing ${ }^{4}$, highlight the importance of national-to-international interactions but do not address subnational-to-international spillovers. Furthermore, most studies focus on current and historic spillovers and interactions rather than impacts of future actions (with Kroll et al. ${ }^{8}$ providing a valuable exception comparing national SDG progress over time) ${ }^{9}$.

These knowledge gaps related to cities' spillovers prompt urgent attention for two reasons. First, cities' actions are often atypical of their country contexts, and many decisions that influence global development are made at this sub-national level ${ }^{10}$. An example is climate action. The number of cities and municipalities with ambitious local decarbonization plans is increasing worldwide ${ }^{11}$. While these plans are vital for meeting SDG13 (on climate action), assessing and managing the spillovers that their implementation may create should also be a priority (Box 1). Second, since most cities' work to achieve the SDGs still lies ahead ${ }^{12}$, there is an urgent need to increase our ability to predict and manage the spillovers of their future sustainability actions.

We here define spillovers as impacts that: stem from actions by cities in their efforts to progress on the SDGs within their jurisdictions; reach beyond national borders; and affect the opportunities to advance the SDGs in 'spillover-receiving' places (as illustrated in Fig. 1).

We find these international spillovers from cities to be less acknowledged than SDG interactions within cities ${ }^{13}$ and more difficult to capture than spillover from a city to other regions in the same country (as these are expected to be at least indirectly captured in national SDG progress reporting).

We use the term 'city' for all 'local authorities with some level of urban sustainability ambitions'. This definition is partly borrowed from the Covenant of Mayors for Climate and Energy (covenantofmayors.eu) $)^{11}$, but similar definitions exist for members of other sub-national sustainability networks, such as ICLEI-Local Governments for Sustainability (ICLEl.org) and United Cities and Local Governments (UCLG.org), as well as for the target institutions for SDG Voluntary Local Reviews ${ }^{13}$. This is a broad definition of cities in demographic and jurisdictional terms but with focused scope on 'cities' that claim active interest in contributing to the 2030 Agenda.

In this comment, we argue that if SDG targets can be advanced in these cities with or without certain spillovers, then seeking sustainability strategies that support positive and mitigate negative spillovers is vital to bridge the gap between the 2030 Agenda's ethos of 'global indivisibility and universality' ${ }^{1}$ and its localized implementation.

Key challenges and priorities in making spillover considerations feasible in cities are described in the following sections. These were identified as follows. First, relevant academic and gray literature was reviewed to capture previous studies and frame the challenge and the research question of 'how can research and governance enable accounting for the international spillovers of cities' SDG actions'. The research question was then discussed in workshop settings with selected experts in the field. The experts are academics and civil servants comprising a multi-disciplinary background (including engineering, natural and social sciences) with extensive experience on issues relating to sustainable planning and management of SDG actions. Through facilitated

\footnotetext{
${ }^{1}$ Department of Energy Technology, KTH Royal Institute of Technology, Stockholm, Sweden. ${ }^{2}$ Stockholm Resilience Centre, Stockholm University, Stockholm, Sweden. ${ }^{3}$ Centre d'Études et de Recherches sur le Développement International, CERDI, Université Clermont Auvergne, Clermont-Ferrand, France. ${ }^{4}$ Stockholm Environment Institute, Stockholm, Sweden. ${ }^{5}$ Department of Physical Geography, Stockholm University, Stockholm, Sweden. ${ }^{6}$ Department of Sustainable Development, Environmental Sciences and Engineering, KTH Royal Institute of Technology, Stockholm, Sweden. ${ }^{7}$ Department of Geography, Loughborough University, Loughborough, United Kingdom. ${ }^{8}$ Centre for Environmental Policy, Imperial College London, London, United Kingdom. ${ }^{9}$ Department for Regions and Environment, Statistics Sweden, SCB, Stockholm, Sweden. ${ }^{\circledR}$ email: rebecka. engstrom@energy.kth.se
} 
discussion, research and governance priorities were selected and elaborated.

\section{THE CHALLENGES IN ACCOUNTING FOR CITIES' SPILLOVERS}

Several challenges are present for spillover accounting in cities. First, local decision-makers stand largely unaccountable for the spillovers of their decisions, since nation-states are the formal signatories to the 2030 Agenda. Second, delivering on existing local mandates is challenging enough in most cities, with often limited financial and human resources ${ }^{14}$. Adding SDG considerations to city development plans is already increasing that load, without considering spillovers. Third, even where there is will and resources, it is inherently difficult to assess the spillovers from cities' future SDG actions. Although physical-economic modeling can estimate some of the impacts of international trade, there are no widely established methods or data standards for tracing impacts arising from changes at the level of cities across national borders. Uncertainties are unavoidable, and increase when moving from assessing current and past developments to future impacts $^{5}$.

Spillovers from local action also pinpoint a key implementation challenge embedded in the 2030 Agenda. In contrast to their

\section{Box 1: An SDG-spillover case study from southern Sweden}

The municipality of Oskarshamn, Sweden, aims to become climate neutral by year 2030. This requires decarbonizing local transport, industry, agriculture and energy use in buildings.

A study ${ }^{5}$ of the potential impacts on water and land use from various decarbonization pathways shows that increased electrification of the local community would increase water and land use within Sweden, while increased local use of biofuels would increase water and land use abroad. However, both strategies meet local policy makers' goal of climate neutrality.

Translating these findings to impacts on SDGs, one strategy to decarbonize Oskarshamn and advance SDG 7 (on clean energy) and SDG 13 (on climate action) could impede progress on targets within other goals, such as SDG15.1 (on terrestrial biodiversity) and SDG 6.4 (on sustainable water use) in Germany or Brazil-depending on fuel import choices. Another strategy would cause less such international spillovers, since their impacts would primarily be local or national.

The study reveals that both magnitude and geographical distribution of spillovers are strategy-dependent, with complex consequences for global SDG implementation. For example, humid and arid regions differ greatly in their vulnerability to spillover-enhanced consumptive use of water-and thereby in their challenges to achieve SDG6.4. predecessors, the Millennium Development Goals (MDGs), the SDGs require countries in the Global North to push the agenda both through international cooperation and through local action within their own constituencies. While the latter is encouraged to be 'localized" ${ }^{\prime 15}$, the former is typically out of the control, sight and responsibility of cities.

An example of this divergence can be found in Sweden (a frontrunner country in recent SDG-rankings despite relatively significant national-level spillovers ${ }^{4}$ ), where the Politics for Global Development (PGU) strategy was first adopted in 2003 and later incorporated in Sweden's formal adoption of the 2030 Agenda $^{16}$. The core principle of PGU is that all political decisions made in Sweden should be aligned with a sustainable global development. Many Swedish cities are working to "localize the SDGs", but when doing so have no clear procedures for incorporating PGU locally ${ }^{17}$.

Although the Swedish case is not representative to cover the diversity of cities around the globe, many cities have ambitions to contribute to the 2030 Agenda, but similarly lack tools to assess and manage their international spillovers ${ }^{15}$. There is also reason to suspect that the correlation between high SDG performance and large and varied spillovers - as found at national level ${ }^{4}$-also exists at city level ${ }^{18}$. Furthermore, with less than a decade to transform our societies, differentiated action is increasingly necessary.

\section{A RESEARCH AGENDA TO ENABLE SPILLOVER CONSIDERATIONS IN CITY-LEVEL SDG STRATEGIES}

To make international spillovers from cities' SDG action assessable, more integrated research efforts are needed. First, spillover assessment approaches must be fitted to local realities and ongoing efforts on localizing the SDGs. Second, the quantitative assessment of spillovers, where possible, must build on today's state of the art in environmental assessment, energy-economics modeling and socio-ecological systems thinking. Harmonized and coordinated modeling frameworks and data would provide muchneeded comparability of different spillover assessments. Third, time is short - therefore, strategic prioritization of which SDGs and which spillovers to address first is vital. This includes identifying how best to acknowledge city spillovers in assessments of SDG progress at all scales.

Fit spillover assessments to local realities

In order to make spillover assessments feasible and actionable, decision-makers need analyses that are specific to their decision

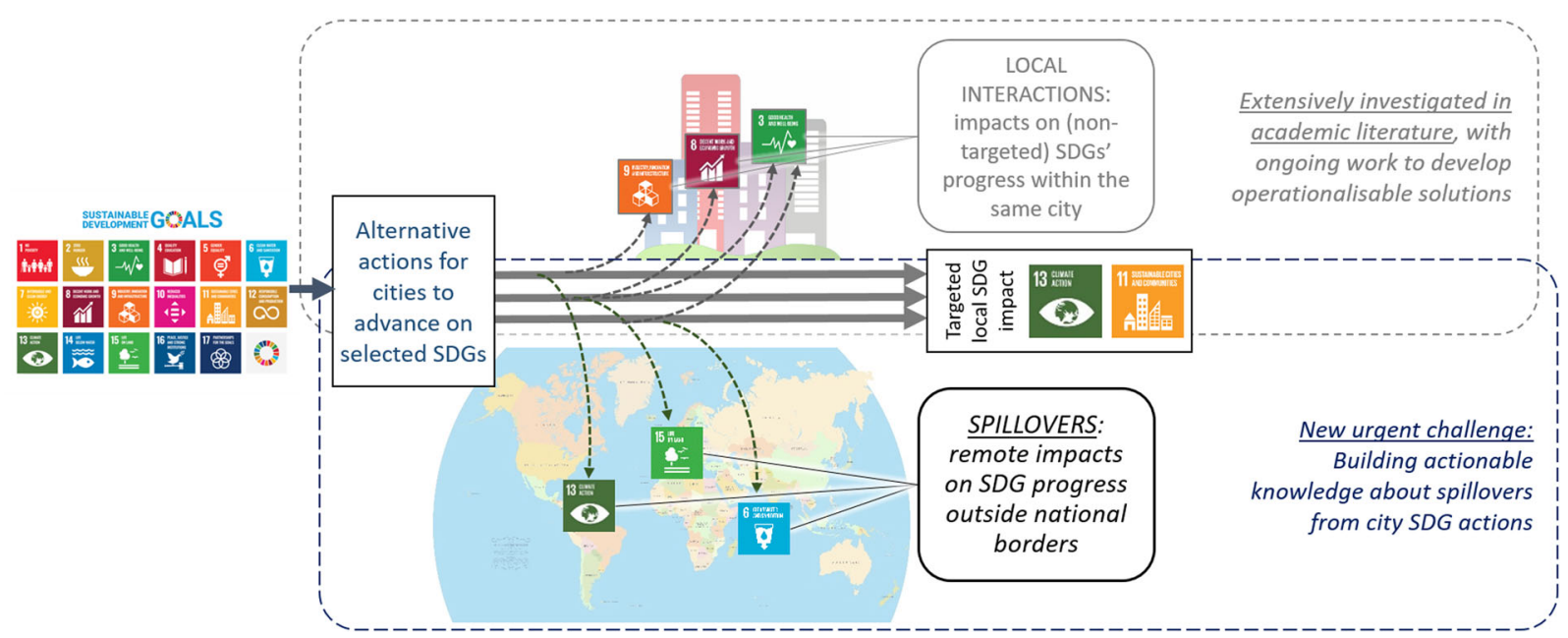

Fig. 1 Graphical definition of spillovers and the challenge they pose related to cities' SDG efforts. Bold arrows represent direct targeted impacts of local action towards selected SDGs. Dashed arrows pointing upwards represent non-targeted impacts that happen locally on SDGs achievements. Dashed arrows pointing downwards represent spillovers. 
Table 1. Sample of established methods with participatory approaches in science-policy-society integrated assessments.

\begin{tabular}{|c|c|c|}
\hline Methodology & Key participatory approach & Example References \\
\hline $\begin{array}{l}\text { Target-seeking scenario } \\
\text { modeling }\end{array}$ & $\begin{array}{l}\text { Ensemble approaches to quantitative and spatialised } \\
\text { integrated modeling (currently usually expert-led energy- } \\
\text { economics; now expanding to } 2030 \text { Agenda needs) }\end{array}$ & $\begin{array}{l}\text { LeClere, D. et al. (2020) Bending the curve of terrestrial } \\
\text { biodiversity needs an integrated strategy. Nature } \mathbf{5 8 5} \text {, } \\
551-556\end{array}$ \\
\hline $\begin{array}{l}\text { Sustainability futures and } \\
\text { visioning }\end{array}$ & $\begin{array}{l}\text { Dialog-based processes for social learning and } \\
\text { transformative change. Focus on multiple perspectives } \\
\text { and grounding in culture-contingent narratives. }\end{array}$ & $\begin{array}{l}\text { Collste, D. et al. (2019) Three horizons for the sustainable } \\
\text { development goals: a cross-scale participatory approach } \\
\text { for sustainability transformations. doi: 10.31235/osf.io/ } \\
\text { uhskb. Preprint, SocArxiv }\end{array}$ \\
\hline
\end{tabular}

contexts. Assessment tools and focus of analysis must be adapted to local social, economic and environmental challenges and levels of development. Assessment approaches must also be tailored to the existing capacity of city governments. This includes effectively identifying when, where and how spillovers should be considered within local planning practices.

For that to happen, participatory approaches for untangling spillovers are of crucial importance. Such approaches are triedand-tested ways to facilitate learning and deal with diverse local contexts (examples in Table 1), but are still poorly integrated into the larger-scale assessments that dominate the SDG research field ${ }^{9}$. User-friendly, transparent tools and interfaces could be of great benefit to make the likely complex spillover consideration practical across diverse expert groups and with lay users ${ }^{19}$. However, any process for 'rapid assessment' of spillovers must be balanced with longer-term decision-support approaches that avoids the dangers of over-simplification.

Given the strategy-dependence of spillovers, their localized assessment must lastly enable evaluation of alternative SDG actions to support comparison of impacts on directly targeted vs. indirectly affected SDGs. This should also facilitate multi-perspective analysis of local vs. global and near-term vs. long-term priorities.

Increase accessibility, comparability, and transparency of tools The above envisioned local spillover assessments rely on availability of interchangeable tools, subject to topic of analysis, data availability, time and resources. Since 2015, the scientific community has presented a plethora of methods for assessing how SDGs can be met and how they relate to each other. Most of these have focused on qualitative or semi-quantitative assessments ${ }^{9}$. There are however several methods that could be used for assessing spillovers in a quantitative way, as exemplified by for example Wood et al. ${ }^{20}$, Sridharan et al. ${ }^{21}$, and Pedercini et al. ${ }^{22}$. These build on sustainability assessment tools that have evolved over decades. With their evolution, model complexity, data demands, and computational time have grown. To enable quantitative spillover analysis of local actions and facilitate meaningful comparison between analyses, we call for the following strategic research coordination priorities.

1. Increase international collaboration on data gathering and sharing to improve open accessibility of information needed for SDG spillover assessments. This should build on the FAIR data principles ${ }^{23}$. It should also acknowledge and aim to mitigate the inequity in capacities in different parts of the world to collate and assess local level SDG related data.
2. Encourage multi-model coordinated SDG implementation assessments, taking inspiration from model intercomparison projects for climate change ${ }^{24}$ and the new challenges of human-perturbed earth system dynamics ${ }^{25}$. This should include aligning scopes and defining common baseline scenarios and key assumptions across models, while allowing for variations in process representations and resolutions. All models have inherent limitations in their representations of reality. Comparing results would therefore not only enrich model analyses and offer complementary perspectives. It could hopefully also provide a more comprehensive understanding of spillover dynamics.

3. Increase capacity to highlight and handle uncertainty. Acknowledging elements that are only partially quantifiable and where considerable irreducible uncertainties remain helps avoid over-simplification or flawed optimizations. Engaging widely, including through citizen science, could help characterize unavoidable uncertainties in ways that can inform us about qualities of the systems we analyze and give important insights to improve adaptive management and system resilience ${ }^{26}$.

To be effective, these efforts should be shared in open scientific knowledge hubs, building on or inspired by existing platforms such as the CMIP (www.wcrp-climate.org) and IAMC (www. iamconsortium.org). There, data, model results and problem tackling methods for SDG spillovers processes could be uploaded, discussed, and compared.

\section{Guide prioritization}

Finally, consideration of spillovers must be made possible without overwhelming local planners and decision-makers in never-ending cross-border SDG impact analyses. This demands that the international research community reconciles current knowledge and guides analysis to where it is most impactful. An important, third effort is therefore to review and identify SDG targets, actions and localities that are most likely to create the largest spillovers, as well as those most sensitive to the impacts of spillovers.

Clues to identifying these can be found in recent research and the 2030 Agenda itself. The vulnerability of Least Developed Countries is one example ${ }^{1}$. The importance of reducing the environmental footprint of consumption - and achieve SDG12 on sustainable production and consumption - in wealthier countries, is another ${ }^{27,28}$.

A consolidation of recent mappings of SDG interactions and spillover evaluations (including, for example, work of refs. ${ }^{8,22,29-31}$ ) should also 
Box 2: Three research needs to enable spillover governance

Three research efforts are urgently needed to enable consideration and accounting of the international spillovers from cities' SDG actions.

Fit approaches to local realities

- Develop analyses specific to city decision contexts, including government capacity and planning processes.

- Make assessments adaptable to local social economic and environmental challenges.

- Participatory approaches, engaging diverse groups of experts, as well as laypersons, will be crucial to achieve this.

Increase accessibility, comparability, and transparency of tools

- Increase international collaboration on and open access to data, to improve quantitative analysis, as well as to mitigate global inequities in data access.

- Build multi-model coordination, to enable comparisons of complementary perspectives across models.

- Acknowledge uncertainties, as means to help analysts avoid oversimplification and give insights on the partially unquantifiable qualities of the systems under analysis.

Reconcile available knowledge to guide prioritization

Review and identify SDG targets, actions and localities that:

- are most likely to create the largest spillovers; and

- are most sensitive to the impacts of spillovers.

The first would benefit from an inclusion of spillovers in established SDG monitoring procedures. The second should include identifying SDG targets that may condition the whole 2030 Agenda locally.

help highlight goals that condition the whole Agenda. We anticipate that progress on, for example, poverty eradication (SDG1), sustainable energy access (SDG7) and non-violence (included in SDG16) are prerequisites for local progress on most other SDGs. Verifying these and identifying additional 'overriding targets' could help pinpoint and prioritize spillovers that either halt or advance their progress (and hence should be minimized or maximized).

The current global pandemic has also been a stark reminder of the importance to safeguard health (and SDG3) in order to progress on other SDGs. Our shared vulnerability to the significant disruptions from new communicable diseases in a globalized economy reveals for example the dependence of developed and developing countries alike on globalized supply chains ${ }^{32}$.

Lastly, we call for an inclusion and prioritization of spillovers in established accounting procedures. We have to date found no indicators for local monitoring of SDG progress that captures spillovers $^{13,17}$. As a start, formal SDG indicators ${ }^{33}$ with strong links to spillovers, together with proposed spillover indicators ${ }^{4}$, should be highlighted and prioritized in local, as well as national and global progress reporting.

\section{A CALL FOR EXPANDED RESPONSIBILITIES}

Our comment is a call for research priorities to enable and empower cities to account for the spillovers of their local 2030 Agenda implementation strategies (summarized in Box 2). Many cities with large and varied spillovers have high ambitions to contribute to global sustainability. Availability of tools, guidance and incentives is vital to enable them to address their spilloversand should be included in emerging sub-national guidelines on localizing the SDGs ${ }^{13}$. We believe that the above-mentioned research agenda can deliver critically missing tools and guidance.

To also enhance incentives, we encourage communities of cities (such as the UCLG or ICLEI) to take up the spillover challenge. Bringing experiences and ambitions together would raise the profile of spillover management and promote the ethical dimensions of the 2030 Agenda at local level. It could also help expand the mandates of local decision-makers.

However, addressing spillovers at the local level is no silver bullet for effective SDG implementation. International diplomacy, cooperation and development finance are also crucial to mitigate negative spillovers ${ }^{4}$. The efforts to address international spillovers of cities that we call for here must therefore be accompanied by ongoing work by nation states and international actors to strengthen the authority and ambitions of international negotiations and treaties on sustainable development. This includes strengthening the implementation process of the 2030 Agenda as a whole. Furthermore, international partnerships that improve institutional capacity in Least Developed Countries and incorporate norms of good governance, in line with SDG16 and SDG17 will be crucial $^{34}$. This includes delivering on international development support targets already embedded in the agenda ${ }^{29}$.

Spillover consideration, in the form discussed here, may seem like a cumbersome add-on that risks delaying local action on the 2030 Agenda. However, we believe that the here proposed efforts to enable accounting of city spillovers can also be employed to improve the management of SDG interactions locally, and support consideration of spillovers from nations and trans-national regions. Furthermore, a focus on spillovers of SDG implementation in cities could strengthen the Agenda's ethos of universality and indivisibility 'on the ground'. Time is short, and local actions to advance the SDGs should be encouraged. Still, when doing so, we must ensure that local advancements aggregate to global progress.

\section{DATA AVAILABILITY}

No new datasets were generated or analyzed during this study

Received: 13 July 2020; Accepted: 28 November 2020; Published online: 27 April 2021

\section{REFERENCES}

1. United Nations, G. A. Transforming our world: The 2030 agenda for sustainable development. https://sustainabledevelopment.un.org/post2015/transformingour world (2015).

2. Nilsson, M., Griggs, D. \& Visbeck, M. Policy: map the interactions between Sustainable Development Goals. Nature News 534, 320 (2016).

3. SDG Watch Europe. Who is Paying the Bill? (Negative) impacts of EU policies and practices in the world. https://www.sdgwatcheurope.org/who-is-paying-the-bill/.

4. Sachs, J. et al. The Sustainable Development Goals and COVID-19. https://s3.amazonaws. com/sustainabledevelopment.report/2020/2020_sustainable_development_report. pdf (2020)

5. Engström, R. E. et al. Cross-scale water and land impacts of local climate and energy policy - a local swedish analysis of selected SDG interactions. Sustainability 11, 1847 (2019).

6. Nerini, F. F. et al. Connecting climate action with other sustainable development goals. Nat. Sustain. 2, 674-680 (2019).

7. Jaramillo, F. et al. Priorities and interactions of sustainable development goals (SDGs) with focus on wetlands. Water 11, 619 (2019).

8. Kroll, C., Warchold, A. \& Pradhan, P. Sustainable development goals (SDGs): are we successful in turning trade-offs into synergies? Pal. Commun. 5, 1-11 (2019).

9. Bennich, T., Weitz, N. \& Carlsen, H. Deciphering the scientific literature on SDG interactions: a review and reading guide. Sci. Total Environ. 728, 138405 (2020).

10. Tavares, R. Paradiplomacy: Cities and States as Global Players (Oxford University Press, 2016).

11. Covenant of Mayors. Covenant of Mayors Initiative. https://www.covenantofmayors.eu/ about/covenant-initiative/origins-and-development.html (2020).

12. United Nations. Decade of Action-United Nations Sustainable Development. https://www.un.org/sustainabledevelopment/decade-of-action/ (2019).

13. United Cities and Local Governments \& UN-HABITAT. Guidelines for Voluntary Local Reviews. https://issuu.com/uclgcglu/docs/uclg_virlab_guidelines_2020_volume_i (2020).

14. Davey, K. Local Government in Critical Times: Policies for Crisis, Recovery and a Sustainable Future. https://www.ccre.org/docs/Local_Government_in_critical_times.EN. pdf (2011).

15. Global Taskforce of Local and Regional Governments. Towards the Localization of the SDGs - How to Accelerate Tranformative Actions in the Aftermath of the COVID-19 Outbreak. https://www.global-taskforce.org/sites/default/files/2020-07/Towards\% 20the\%20Localization\%20of\%20the\%20SDGs.pdf (2020). 
16. Swedish Government. Politiken för Global Utveckling I Genomförandet Av Agenda-2030. https://www.regeringen.se/4952fb/contentassets/7af580b7bee2454eb8ae3fd57252 5654/politiken-for-global-utveckling-i-genomforandet-av-agenda-2030-skr-201718.146.pdf (2018)

17. RKA. Agenda 2030 Nyckeltal för Kommuner Och Regioner, Vägledning 2019. http:// www.rka.nu/download/18.170827ac169d8ecd224727f9/1554462314899/V\%C3\% A4gledning\%20Agenda\%202030,\%2020190405\%20ver\%201.1.pdf (2019).

18. Sudmant, A., Gouldson, A., Millward-Hopkins, J., Scott, K. \& Barrett, J. Producer cities and consumer cities: Using production- and consumption-based carbon accounts to guide climate action in China, the UK, and the US. J. Clean. Prod. 176, 654-662 (2018)

19. Page, J. et al. Open-source planning support system for sustainable regional planning: a case study of Stockholm County, Sweden. Environ. Plan. B. https://doi. org/10.1177/2399808320919769 (2020).

20. Wood, R. et al. Beyond peak emission transfers: historical impacts of globalization and future impacts of climate policies on international emission transfers. Climate Policy 20, S14-S27 (2020).

21. Sridharan, V., Shivakumar, A., Niet, T., Ramos, E. P. \& Howells, M. Land, energy and water resource management and its impact on GHG emissions, electricity supply and food production- Insights from a Ugandan case study. Environ. Res. Commun. 2, 085003 (2020).

22. Pedercini, M., Arquitt, S., Collste, D. \& Herren, H. Harvesting synergy from sustainable development goal interactions. PNAS 116, 23021-23028 (2019).

23. Wilkinson, M. D. et al. The FAIR guiding principles for scientific data management and stewardship. Sci. Data 3, 160018 (2016).

24. World Climate Research Programme. Coupled Model Intercomparison Project (CMIP). https://www.wcrp-climate.org/wgcm-cmip (2020).

25. IIASA. Earth and Human System Modeling Intercomparison Project (EHSMIP). https://iiasa.ac.at/web/home/research/researchPrograms/Energy/Research/ EHSMIP.html (2020)

26. Azcárate, J., Balfors, B., Bring, A. \& Destouni, G. Strategic environmental assessment and monitoring: Arctic key gaps and bridging pathways. Environ. Res. Lett. 8, 044033 (2013)

27. Amos, R. \& Lydgate, E. Trade, transboundary impacts and the implementation of SDG 12. Sustain. Sci. https://doi.org/10.1007/s11625-019-00713-9 (2019).

28. Palm, V. et al. Environmental pressures from Swedish consumption-a hybrid multi-regional input-output approach. J. Clean. Product. 228, 634-644 (2019).

29. Schmidt-Traub, G., Hoff, H. \& Bernlöhr, M. International spillovers and the Sustainable Development Goals (SDGs). https://irp-cdn.multiscreensite.com/ be6d1d56/files/uploaded/SDSN-Policy-Brief_International-spillovers-and-theSDGs.pdf (2019).

30. Weitz, N., Carlsen, H., Nilsson, M. \& Skånberg, K. Towards systemic and contextual priority setting for implementing the 2030 Agenda. Sustain. Sci. 13, 531-548 (2018).

31. Pradhan, P., Costa, L., Rybski, D., Lucht, W. \& Kropp, J. P. A systematic study of sustainable development goal (SDG) Interactions. Earth's Future 5, 1169-1179 (2017).

32. Zhu, G., Chou, M. C. \& Tsai, C. W. Lessons learned from the covid-19 pandemic exposing the shortcomings of current supply chain operations: a long-term prescriptive offering. Sustainability 12, 5858 (2020).

33. United Nations, G. A. Work of the Statistical Commission Pertaining to the 2030 Agenda for Sustainable Development. https://undocs.org/A/RES/71/313 (2017).

34. Blind, P. K. How Relevant is Governance to Financing for Development and Partnerships? Interlinking SDG16 and SDG17 at the Target Level. https://doi.org/ 10.18356/29bf37d1-en (2020).

\section{ACKNOWLEDGEMENTS}

In addition to the authors, valuable contributions to this paper was made by Björn Hugosson, Head of the Climate Unit at the City of Stockholm's Mayor's Office, who participated in the explorative workshops that formed the core ideas of this piece. The authors further thank Erica-Dawn Egan, Karin Larsdotter, and KTH Sustainability Office for support in arranging the workshops that lead to the here expressed insights. We also thank Jennifer Castor and Kaylyn Bacha for assisting in the workshop and its documentation. R. E. Engström and F. Fuso Nerini acknowledge funding from the Swedish Research Council Formas, grant number 2018-01253. S. E. Cornell acknowledges partial support from the European Research Council under the EU Horizon 2020 research and innovation programme (grant agreement 743080-ERA). H. Carlsen and N. Weitz acknowledge partial support from MISTRAThe Swedish Foundation for Strategic Environmental Research through the research programme MISTRA Geopolitics.

\section{AUTHOR CONTRIBUTIONS}

R.E.E. and M.H. developed the initial conceptualization and hypothesis for this paper. All authors contributed with substantial input to the core content of this paper through explorative workshops, each bringing a unique perspective and experience of the issue discussed. R.E.E., D.C., and F.F.N. wrote the first draft of the text. All authors reviewed and actively contributed to the writing, review, and editing of the final version of the text. R.E.E., G.F., M.H., and G.D. contributed with project administration.

\section{COMPETING INTERESTS}

The authors declare no competing interests.

\section{ADDITIONAL INFORMATION}

Correspondence and requests for materials should be addressed to R.E.E.

Reprints and permission information is available at http://www.nature.com/ reprints

Publisher's note Springer Nature remains neutral with regard to jurisdictional claims in published maps and institutional affiliations.

(c) (i)

Open Access This article is licensed under a Creative Commons Attribution 4.0 International License, which permits use, sharing, adaptation, distribution and reproduction in any medium or format, as long as you give appropriate credit to the original author(s) and the source, provide a link to the Creative Commons license, and indicate if changes were made. The images or other third party material in this article are included in the article's Creative Commons license, unless indicated otherwise in a credit line to the material. If material is not included in the article's Creative Commons license and your intended use is not permitted by statutory regulation or exceeds the permitted use, you will need to obtain permission directly from the copyright holder. To view a copy of this license, visit http://creativecommons. org/licenses/by/4.0/.

(c) The Author(s) 2021 